\title{
PLANEJAMENTO MUNICIPAL: uma análise a partir do plano de ações articuladas (par) no Estado do Maranhão
}

\author{
Karla Cristina Silva Sousa ${ }^{1}$ \\ Maria José Pires Barros Cardozo²
}

\section{RESUMO}

O presente artigo discorre sobre o Plano de Ações Articuladas (PAR), a partir de pesquisa realizada em 4 (quatro) municípios do Estado do Maranhão (Cantanhede, Vargem Grande, Palmeirândia e Presidente Vargas). Realizou-se pesquisas bibliográfica, documental e de campo, mediante a aplicação de entrevistas. Discorre-se sobre a questão do planejamento e autonomia municipal, destacando o regime de colaboração e apresenta-se dados da pesquisa sobre o PAR e sua repercussão no planejamento educacional das Secretarias Municipais de Educação (SEMEDs) pesquisadas. Conclui-se que o PAR, nas SEMEDs investigadas, caracteriza-se pelo caráter constrangedor do modelo de planejamento educacional, com base no gerencialismo que, enfatiza a eficiência, a produtividade e os indicadores educacionais.

Palavras-chave: Plano de Ações Articuladas. Planejamento Educacional. Regime de Colaboração.

\section{MUNICIPAL PLANNING: an analysis from the articulated action plan (par) in}

\section{the State of Maranhão}

\begin{abstract}
This article discusses the Articulated Actions Plan (PAR), based on research carried out in 4 (four) municipalities in the State of Maranhão (Cantanhede, Vargem Grande, Palmeirândia and Presidente Vargas). Bibliographical, documentary and field research was carried outthrough the application of interviews. There is a discussion on the issue of municipal planning and autonomy, highlighting the collaboration regime, and data on research on PAR and its repercussion in the educational planning of the Municipal Education Departments (SEMEDs) researched. It is concluded that the PAR, in the SEMEDs investigated, is characterized
\end{abstract}

\footnotetext{
1 Doutora em Educação (UFRN). Professora do Programa de Pós-graduação em rede Mestrado Profissional do Ensino de Física da Universidade Federal do Maranhão/São Luís/Brasil (UFMA). ORCID iD: https://orcid.org/0000-0003-2310-8543. E-mail: sousa.karlla@gmail.com

2 Doutora em Educação (UFCE). Professora do Programa de Pós-graduação em Educação da Universidade Federal do Maranhão/São Luís/Brasil (UFMA). ORCID iD: https://orcid.org/0000-0003-0059-7006. E-mail: isoamri@bol.com.br
} 
by the embarrassing nature of the educational planning model based on managerialism that emphasizes efficiency, productivity and educational indicators

Keywords: Plan of Articulated Actions. Educational Planning. Regime of Collaboration.

\section{PLANIFICACIÓN MUNICIPAL: un análisis a partir del plan de acciones articuladas (par) en el Estado del Maranhão}

\section{RESUMEN}

Este artículo discute el Plan de Acciones Articuladas (PAR), basado en la investigación llevada a cabo en 4 (cuatro) municipalidades del Estado de Maranhão (Cantanhede, Vargem Grande, Palmeirândia y Presidente Vargas). La inv estigación bibliográfica, documental y de campo se llevó a cabo a través de la aplicación de entrevistas. Se discute el tema de la planificación y autonomía municipal, destacando el régimen de colaboración y los datos de investigación sobre PAR y su repercusión en la planificación educativ a de los Departamentos de Educación Municipal (SEMED) investigados. Se concluye que el PAR, en los SEMEDs investigados, se caracteriza por la vergonzosa naturaleza del modelo de planificación educativa, basado en el gerencialismo que enfatiza la eficiencia, la productividad y los indicadores educativ os

Palabras clave: Plan de acciones articuladas. Planificación educativa. Régimen de colaboración.

\section{INTRODUÇÃO}

Este artigo analisa questões referentes ao Plano de Ações Articuladas (PAR), no âmbito do planejamento educacional no Brasil, situando o contexto do Plano de Desenvolvimento da Educação (PDE), criado em 2007, cujo aporte teórico está ligado a um modelo sistêmico de educação e de planejamento baseado na racionalidade técnica e no controle do governo federal sobre os municípios.

O estudo faz parte do projeto de pesquisa denominado "A GESTÃO EDUCACIONAL NAS SECRETARIAS MUNICIPAIS DE EDUCAÇÃO DA REGIÃO METROPOLITANA DE SÃO LUÍS: delineando o caráter de demos constraining da União a partir do Plano de Ações Articuladas (PAR) no período de 2007 2017" financiado pela Fundação de Apoio à Pesquisa no Estado do Maranhão (FAPEMA), cujo objetivo principal é analisar a gestão educacional das Secretarias Municipais de Educação na região metropolitana de São Luís 
a partir do Plano de Ações Articuladas (2007-2017), evidenciando o papel da União nesta política.

Analisamos a Gestão Educacional tomando por base as proposições contidas para a gestão nas normativas que compõem o Plano de Ações Articuladas (PAR). Observamos mais de perto como as SEMEDs da região metropolitana de São Luís organizaram suas formas de gerenciar a educação, visto que o PAR possui uma proposta específica de gestão da educação materializada na gestão por resultados. Para tanto, adotamos duas hipóteses:

1. O governo federal brasileiro não é uma democracia constrangida (demos constraining) em relação aos subgovernos nacionais, o que o faz legislar em primazia políticas educacionais como o PAR que interfere na gestão educacional dos subgovernos nacionais, transformandoos em meros executores.

Neste sentido, O PAR cerceia a autonomia destes e superimpõe a gestão por resultados como parâmetro para a melhoria da qualidade da educação. O PAR não efetiva a gestão por resultados e nem as SEMEDs conseguem propor a sua concepção de gestão educacional, criando um hibridismo que ora pende para o gerencialismo e performatividade, ora para a burocracia, ora para total atuação descoordenada e desarticulada.

2. O federalismo brasileiro é incompleto, recaindo na armadilha da decisão conjunta (jogo de empurra), sendo o PAR uma arena de negociações conflitante entre União e subgovernos nacionais. Esta arena de negociações com a adoção do PAR pelos municípios traz para estes o jogo de soma zero, em que não há efetiva colaboração entre as partes envolvidas.

Na perspectiva de impasse entre uma concepção burocrática, uma democrática e uma gerencial o Brasil adot ou o Plano de Ações Articuladas (PAR) no ano de 2007 que tem em seu texto normativo a pretensão de superar o imobilismo da gestão burocrática. Seu foco foi trazer para as SEMEDs uma gestão gerencial em perspectiva sistêmica. 
Destacamos que ultimamente o objetivo democrático que pauta a gestão educacional das atuais políticas educacionais brasileiras aponta a transposição das práticas administrativas de gestão empresarial como a melhor opção para o setor público: a gestão burocrática desenvolvida pelas instituições públicas seria ineficiente e a gestão gerencial privada mais eficaz.

Com essa visão, o Plano de Ações Articuladas é superimposto às SEMEDs como a melhor forma de planejar e organizar as ações de gestão educacional, por prever ações e subações gerenciáveis e executáveis que garantem a gestão de resultados e, consequentemente, a democratização da educação, melhoria do IDEB e pactuação do regime de colaboração. Figurando como a única opção saudável de gestão da educação para os subgovernos nacionais.

A partir da problemática exposta temos como questão central para a pesquisa saber: como foi organizada a gestão educacional das Secretarias Municipais de Educação (SEMEDs) da região metropolitana de São Luís a partir do Plano de Ações Articuladas (2007-2017) que possui proposta educacional baseada na gestão por resultados, considerando o papel da União nesta política?

Diante destas especificidades da gestão educacional no Brasil e da adoção do PAR para estruturar e organizar a gestão da educação, elegemos a gestão educacional desenvolvida pelas SEMEDs como objeto de estudo desta pesquisa.

O texto mostra de modo específico os delineamentos do PAR a partir de pesquisa desenvolvida em 4 (quatro) municípios do Estado do Maranhão (Cantanhede, Vargem Grande, Palmeirândia e Presidente Vargas). Realizamos pesquisa bibliográfica, documental e de campo, mediante a aplicação de entrevistas com 3 (três) Coordenadores Locais do PAR, 4 (quatro) Secretários Municiais de Educação e 2 (dois) Técnicos do MEC.

O Estudo foi organizado em duas partes. Na primeira, discorremos sobre alguns aspectos do planejamento educacional no Brasil, enfocando a questão do planejamento municipal e suas implicações para a autonomia 
dos municípios. Na segunda, analisamos o PAR e sua repercussão no planejamento educacional das Secretarias Municipais de Educação, destacando as questões referentes à quatro secretarias municipais de educação do Estado do Maranhão.

Os dados das entrevistas apontaram uma concepção do PAR como mecanismo de constrangimento do governo federal para seus subgovernos nacionais no que se refere à autonomia do modelo de planejamento contido no PAR. Inferimos, também, que o PAR caracteriza-se pelo caráter constrangedor (constraining) do modelo de planejamento educacional, baseado no gerencialismo que enfatiza a eficiência, a produtividade e os indicadores educacionais dos Sistemas Municipais de Educação (SME.)

\section{PLANEJAMENTO EDUCACIONAL E A AUTONOMIA DOS MUNICÍPIOS}

O Planejamento educacional compreende um processo político, técnico e institucional, por meio do qual se realiza a análise da realidade, determinam-se diretrizes, metas e prioridades de cada ente federado. No que se refere aos municípios brasileiros, à questão do planejamento articulou-se com as lutas pela autonomia dos mesmos, iniciadas a partir de 1980, no contexto dos movimentos que reivindicavam a redemocratização e a repolitização da sociedade brasileira, a defesa da escola pública, a gestão democrática da educação, a municipalização, a descentralização da educação, o fortalecimento do poder local e a participação da sociedade civil na definição, controle e avaliação das políticas educacionais.

Nesse contexto, Gadotti e Romão (1993), pontuam que em 1986 a realização do I Encontro Nacional de Dirigentes Metropolitanos de Educação em Recife, fortalecendo o movimento em favor da autonomia municipal, com mobilização dos dirigentes municipais de educação que culminou com a criação da União Nacional dos Dirigentes Municipais de Educação (Undime).

A criação da Undime foi um passo importante para a valorização do planejamento da educação nos municípios, pois possibilitou aos Secretários 
de Educação Municipais a formação no sentido de desenvolver a capacidade de direção, administração e controle das políticas educacionais dos municípios. Ou seja, propiciou a elaboração de planos e projetos referentes à educação infantil e ao ensino fundamental.

A responsabilidade dos municípios pela educação infantil e o ensino fundamental atende ao preceito da Constituição da República Federativa do Brasil (CRFB) de 1988 que no art. 211, § 2º, enfatiza que os Municípios atuarão prioritariamente no ensino fundamental e na educação infantil. Da mesma forma a Lei de Diretrizes e Bases da Educação (LDBEN) n 9.394 de 1996, determina no art. 11 que os Municípios incumbir-se-ão de:

1 - organizar, manter e desenvolver os órgãos e instituições oficiais dos seus sistemas de ensino, integrando-os às políticas e planos educacionais da União e dos Estados;

II - exercer ação redistributiva em relação às suas escolas;

III - baixar normas complementares para os seus sistemas de ensino;

IV - autorizar, credenciar e supervisionar os estabelecimentos do seu sistema de ensino [...] (BRASIL, 1996).

Com base nesses preceitos legais (CRFB e LDBEN n 9.394/1996), destacamos que cabe ao município a coordenação da política educacional sob sua responsabilidade em regime de colaboração com a União e os Estados.

Para tanto, a CRFB no art. 18 confere a autonomia do município como ente jurídico-político de direito público interno (CURY, 2014). A autonomia dos municípios está articulada à criação dos seus Sistemas Municipais da Educação (SME), ou a opção por integrar-se aos sistemas dos Estados, conforme dispõe o art. $8^{\circ}$ da LDBEN (Lei n 9.394/96):

A União, os Estados, o Distrito Federal e os Municípios organizarão, em regime de colaboração, os respectivos sistemas de ensino.

$\S 1^{\circ}$ Caberá à União a coordenação da política nacional de educação, articulando os diferentes níveis e sistemas e exercendo função normativa, redistributiva e supletiva em relação às demais instâncias educacionais.

$\S 2^{\circ}$ Os sistemas de ensino terão liberdade de organização nos termos desta Lei (BRASIL, 1996). 
Desse modo, se o município tem a prerrogativa de optar pela criação do seu sistema de educação, ele deve estabelecer relações de cooperação e não mais de dependência. Ou seja, a instituição do SME permite que ele se subordine somente às leis e diretrizes nacionais, atuando em "regime de colaboração, não mais de subordinação, com o estado" (BORDIGNON, 2009, p. 35).

Legalmente, segundo a douta norma, o município terá autonomia para elaborar suas políticas, responsabilidades, finalidades e leis referentes à educação municipal. Ao constituir seu sistema, o município poderá organizar e planejar as ações educacionais de sua competência.

Ao planejar as suas ações o município deve considerar $\circ$ planejamento como um processo de elaboração e execução de políticas que transformem a educação municipal e, que se configure como um referencial para a tomada das decisões.

Sem planejamento o município fica à mercê de ações improvisadas, personalistas, sem visão estratégica e sistêmica. Como acentua Saviani (2010, p. 782), "sistema de ensino significa, assim, uma ordenação articulada dos vários elementos necessários à consecução dos objetivos educacionais preconizados para a população à qual se destina. Supõe, portanto, o planejamento".

Corroborando com essa perspectiva, Cabral Neto et. al. (2016, p. 50) pontuam que:

[...] os planos estaduais e municipais de educação se tornam peças importantes no processo de configuração do sistema nacional de educação na medida em que se constituem em elos essenciais na viabilização do regime de colaboração e, por conseguinte, na materialização das metas do PNE.

Portanto, o Plano Nacional de Educação (PNE), aprovado em 25 de junho de 2014 pela Lei $n^{\circ} 13.005$, define no art. $7^{\circ}$ o regime de colaboração entre a União, os Estados, o Distrito Federal e os Municípios. Conforme o texto do referente artigo esse regime cooperativo depende do alinhamento dos 
planos de educação nos três entes federados, constituindo-se em um passo importante para a construção do Sistema Nacional de Educação (SNE).

A esse respeito o PNE (2014-2024) apresenta as seguintes ações para a implementação do regime de colaboração:

$\S 5^{\circ}$ Será criada uma instância permanente de negociação e cooperação entre a União, os estados, o Distrito Federal e os municípios.

$\S 6^{\circ} \mathrm{O}$ fortalecimento do regime de colaboração entre os estados e respectivos municípios incluirá a instituição de instâncias permanentes de negociação, cooperação e pactuação em cada estado.

$\S 7^{\circ} \mathrm{O}$ fortalecimento do regime de colaboração entre os municípios dar-se-á, inclusive, mediante à adoção de arranjos de desenvolvimento da educação (BRASIL, 2014, p. 3).

De acordo com o documento publicado pela Diretoria de Articulação com os Sistemas de Ensino do Ministério da Educação (MEC), publicado em 2015, a concretização das metas previstas no PNE (2014-2024) dependerá da articulação dos planos decenais com outros instrumentos de planejamento de governos, tais como os Planos Plurianuais, os Planos de Ações Articuladas e outros instrumentos de financiamento (BRASIL, 2015).

\section{O PLANO de AÇÕES ARTICULAdAS (PAR) E SUA REPERCUSSÃo NO PLANEJAMENTO EDUCACIONAL DAS SECRETARIAS MUNICIPAIS DE EDUCAÇÃO}

Em meados dos anos 90, segundo Schultze (1995), há uma ampliação do federalismo executivo e minimização dos demais poderes, além do fortalecimento do governo federal ante os demais subgovernos nacionais, mediante políticas relacionadas à reforma do Estado que imprimiram uma diminuição de investimentos nas políticas sociais, privatização e terceirização de serviços estatais.

O processo de descentralização defendido após a reforma veio acompanhado da centralização de políticas sociais, ocorrendo a transferência da responsabilidade no tangente à implementação e gestão de políticas e programas que eram definidos em âmbito federal para os subgovernos nacionais. Desta maneira, ao analisar o PAR não se deve perder de vista seu contexto de criação, que se dá imerso a uma crise da 
economia mundial iniciada nos anos de 2000, eclodindo em 2008 (ATALLI, 2009).

Tentando sobreviver à crise econômica mundial iniciada em 2007/2008 e ao aumento das taxas de inflação e desemprego no Brasil, o governo de Luís Inácio da Silva implementou no ano de 2007 o PAC, e, para a área da educação instituiu PDE, cujo motor de execução materializa-se por seu instrumento jurídico denominado de Plano de Ações Articuladas (PAR).

Tomando por base o seu contexto de formulação, compreende-se o PAR não apenas como uma regulamentação federal de transferências de recursos, mas como um conjunto de ações cujo objetivo visou promover a melhoria das relações intergovernamentais, que se materializam no fundamento da gestão compartilhada entre os entes federados, e se constrói sob a forma de pacto federativo dentro de uma arena de negociação instituída pela realidade dos municípios que o executam. Entende-se o PAR enquanto arena de negociação da gestão educacional, cujos representantes são as Secretarias Municipais de Educação (SEMEDs).

Ao buscar analisá-lo enquanto arena de negociação da gestão educacional rumo a um regime de colaboração, surge a dificuldade polarizada no federalismo brasileiro: a centralização/descentralização evidenciadas na path dependence do Brasil em matéria de política educacional. Sob este aspecto pode-se observá-lo como uma nova forma de centralização: considerando suas diretrizes gerais, formas de financiamento e assistência técnica, que são definidos por uma norma geral materializada nas Resoluções $n^{\circ}$ 29/07, n 47/07 e n 14/12 do FNDE. Estas três resoluções são as normativas mais importantes no âmbito do PAR por operacionalizarem legalmente o Decreto $n^{\circ}$ 6.094/07.

Entendemos o PAR como uma arena de negociação do planejamento educacional, cujos representantes são as SEMEDs. Ao buscar analisá-lo enquanto arena de negociação rumo a um regime de colaboração, surge a dificuldade polarizada no federalismo brasileiro: a centralização/descentralização evidenciadas na trajetória dependente do Brasil em matéria de política educacional. 
Sob este aspecto podemos observá-lo como uma nova forma de centralização do planejamento educacional (considerando suas diretrizes gerais, formas de financiamento e assistência técnica, que são definidos por uma norma geral materializada nas Resoluções n 29/07, n 47/07 e n 14/12 do FNDE). Estas três resoluções são as normativas mais importantes no âmbito do PAR por operacionalizarem legalmente o Decreto n 6.094/07.

Na visão do MEC, o Plano de Ações Articuladas é um importante instrumento de macroplanejamento educacional por permitir que os entes federados apontem suas prioridades para que a educação melhore e as metas do IDEB sejam alcançadas.

Com a implantação do PAR, o planejamento educacional acaba tendo uma cooperação coercitiva, não baseada na condição de igualdade entre as partes, já que o documento estabelece, fixa e normatiza como se dará o regime de colaboração, excluindo os estados em detrimento das transferências diretas para o município, sob a premissa da descentralização.

Apresentado como "nova" forma de promover a cooperação no âmbito da educação, deveria pressupor em seus aportes o movimento de parceria entre os governos, cuja negociação estaria na base de compartilhamento de poder entre as partes, pois o compartilhamento de poder é o padrão de interação em uma federação (ELAZAR, 1994; 1995; 1987).

Para dar corpus de legalidade ao Decreto n $n^{\circ} 6.094 / 07$ que instituiu as ações articuladas, a União editou entre os períodos de 2007 a 2015 vinte e duas legislações que corroboram com o texto do referido decreto. Estas vinte e duas normativas estabelecem os critérios e procedimentos a serem executados pela União e os subgovernos nacionais no sentido de operacionalizar o apoio técnico ou financeiro previstos no decreto para os subgovernos nacionais.

A legislação de maior importância em termos de normatividade é a Resolução n 29/07 em virtude de ser nela que estão contidos os critérios e parâmetros para operacionalização do PAR no âmbito do Compromisso 
Todos pela Educação. Ela ficou em vigor durante cinco anos sendo posteriormente revogada pela Resolução de no 14/12.

A resolução no 29/07 traz as condições de participação dos estados, municípios e distrito federal, explicitando a forma de elaboração e apresentação do Plano de Ações Articuladas. Esta resolução é composta por três anexos: ANEXO I - Relação dos estados e municípios; ANEXO II - Eixos temáticos, linhas de ação e itens passíveis de assistência financeira; ANEXO III - Operacionalização da assistência financeira (BRASIL, 2007e).

A normativa $n^{\circ} 29 / 07$ suprime a parte da autonomia dos municípios quando define as formas de participação destes: "Art. 9० As ações que compõem o Compromisso serão implementadas progressivamente $e$ constarão do Plano de Ações Articuladas (PAR), cuja formulação obedecerá aos termos desta Resolução" (BRASIL, 2007e).

Por outro lado, entendemos as ações articuladas enquanto plano estratégico que objetiva promover a descentralização, pelo menos no texto legal. Dentro de sua lógica, os municípios são o local de sua execução e, para além deste aspecto, prevê fóruns de discussão configurados no Comitê Local de Avaliação, cujas esferas da sociedade civil são privilegiadas na participação.

Observamos que no Anexo II - Eixos temáticos, linhas de ação e itens passiveis de assistência financeira, a Resolução n 29/07 mostra sua configuração de Estado regulador e mesmo o modelo de um federalismo dependente, pautado em mecanismo demos constraining, quando delimita os itens que podem ou não ter assistência técnica financeira:

1. Gestão Educacional Gestão Democrática: Articulação e Desenvolvimento dos Sistemas de Ensino:

Apoio técnico e financeiro para a elaboração de instrumentos de Planejamento Estratégico das secretarias Estaduais e Municipais.

Apoio técnico e financeiro para a implantação de Conselhos Municipais de Educação e formação continuada de membros do Conselho.

Apoio técnico e financeiro para a implantação de Conselhos Escolares e formação continuada de membros do Conselho. 
Apoio técnico e financeiro à formação continuada das equipes das secretarias de educação, de gestores educacionais e gestores dos sistemas de ensino que atuam em todas as modalidades da Educação Básica: Educação Especial, Educação do Campo, Educação Indígena, Educação Quilombola, Educação Ambiental, Educação em Direitos Humanos, Educação Integral e Integrada, Educação para a Promoção da Igualdade de Gênero e Diversidade Sexual, Educação em Saúde e Educação de Jovens e Adultos (BRASIL, 2007e, s/n).

O PAR possui, a partir da Resolução n² 29/07, a pretensão de promover a gestão democrática da educação e reúne indicadores que contribuem para uma análise da qualidade da educação dos municípios, por meio do diagnóstico da realidade educacional. Diferencia-se por intentar uma padronização em nível educacional que dá visibilidade ao padrão de qualidade definido na Resolução n² 29/07.

É a tentativa de uma estratégia de materialização do regime de colaboração entre os entes federados, que objetiva possibilitar uma nova lógica de descentralização de recursos voluntários. Na elaboração do PAR o gestor municipal pactua com o MEC os compromissos que irão melhorar os pontos fracos da gestão educacional dos municípios por meio de estratégias previamente definidas. Com ele observamos a indução, por parte do governo federal, da gestão de políticas educacionais nos estados e municípios.

Os entes federados passaram a ser responsabilizados pela qualidade da educação. O gestor do sistema educacional se responsabiliza por implementar suas ações e subações. A partir desta lógica, ocorre a fragmentação do serviço educacional, entendida como a introdução do gerencialismo na educação.

Esta indução aparece também na Resolução n 47/07 do FNDE. Nela, o gerencialismo na educação brasileira apresenta-se do seguinte modo:

Art. 10

$[\ldots]$

Anexo B: Eixos Temáticos, Linhas de Ação e Itens Passíveis de Assistência Técnica e Financeira aos Estados e ao Distrito Federal.

Eixo: 1 Gestão educacional 
Linha de ação: 1 Gestão Democrática dos Sistemas de Ensino Itens:

1.1.1 Elaboração de instrumentos de Planejamento Estratégico das Secretarias de Educação.

[...]

1.2 Desenvolvimento da Educação Básica:

[...]

1.2.3 Elaboração, implantação e acompanhamento dos sistemas de avaliação, utilizando seus resultados como base para 0 planejamento de ações direcionadas para a melhoria da qualidade da educação básica dos Estados e do Distrito Federal (BRASIL, 2007f).

Mister salientar que, no setor educacional, o novo gerencialismo na gestão pública gerou uma fragmentação dos serviços e introduziu a competição entre as escolas, estados e municípios. As influências estão na gestão educacional por meio da descentralização, na instituição dos colegiados, na participação da comunidade escolar nos processos de decisão.

A normativa $n^{\circ} 47 / 07$ do FNDE não deixa opções aos subgovernos nacionais quanto a adesão ou não ao PAR, sendo obrigatória sua elaboração e implementação, com nítida matriz gerencial de gestão por resultados e mensuração de qualidade educacional por sistemas de avaliação direcionados e focalizados por meio do IDEB.

Esta lógica de controle por resultados e foco na avaliação não é algo novo, está presente nos documentos do BM que priorizam a educação básica: "[...] Subjacente à ideia de centralidade, estão os mecanismos de controle sobre os focos de tensões sociais, as políticas de divisão internacional de produção de conhecimentos, a domesticação e manipulação das demandas oriundas da sociedade civil (SILVA, 2002, p.125).

Ao aderi-lo, os entes federados mantêm a concepção de uma política federativa baseada em uma estrutura dual, com previsão de distintos níveis de governo em que uns se dedicam a algumas funções mais gerais (no caso o governo federal), e outros mais locais (aqui são os estados e municípios que de fato o implementam e o executam). 
Este caráter traz à tona uma questão essencial em países federalistas observada por Riker (1964): a necessidade de barganhas, negociações constantes que definem a capacidade de poder de cada uma das instâncias de governo no momento de sua implementação.

Conforme 0 art. $5^{\circ}$ da Resolução $n^{\circ}$ 29/07 do FNDE, inciso II, os subgovernos nacionais são responsáveis apenas pelo recebimento dos recursos financeiros transferidos pelo FNDE, não possuindo qualquer tipo de autonomia para pensar, planejar ou instituir políticas, diretrizes, normatização e coordenação dentro das ações articuladas.

Mesmo se proclamando como uma política cooperativa, materializase na dificuldade do exercício da autonomia dos subgovernos nacionais frente ao centralismo do governo federal em termos de formulação, implementação e avaliação de políticas educacionais, trajetória dependente constante do Brasil. Ou seja, o PAR inviabiliza por meio de suas normativas $n^{\circ}$ 29/07, n 47/07 e $n^{\circ}$ 14/12 o planejamento educacional autônomo dentro das Secretarias Municipais de Educação.

\section{O PLANO DE AÇÕES ARTICULADAS (PAR) E AS SECRETARIAS MUNICIPAIS DE EDUCAÇÃO NO MARANHÃO - O PLANEJAMENTO EDUCACIONAL EM QUESTÃO}

A Secretaria Municipal de Educação é a responsável pela coordenação do processo de implantação e consolidação do PAR na figura do Dirigente Municipal de Educação (Secretário de Educação). Este macroplanejamento técnico parece pretender uma apropriação da gestão intergovernamental para os atores interessados. Se de fato cumprisse este aspecto evitaria rupturas e permitiria negociações permanentes dentro das matrizes teóricas do federalismo cooperativo de Elazar (1995, 1987), Wright (1978) e Pierson (1995).

Pierson (1995) destaca que o federalismo afeta o desenvolvimento das políticas sociais, o grau dependerá das características do sistema federadoe de trajetória dependente. Em nossa visão, o Plano de Ações Articuladas foi prejudicado pelo modelo federativo praticado no Brasil que ora pende para 
a centralização ora para a descentralização, colocando a este um problema de relações intergovernamentais histórico.

O modelo cooperativo ao qual se propõe efetivar deveria conter ações coletivas nesta política, com representação efetiva e participação de todos os entes, desde sua formulação, buscando um compartilhamento de funções, próprio de modelos federativos que possuem relações intergovernamentais verticais e horizont ais coordenadas.

Em modelos federativos de política, como as ações articuladas, a presença na arena política de diferentes atores para sua execução torna complexo seu desenho e operacionalização, pois deve atender múltiplos interesses políticos e capacidades distintivas, complicando sua formulação e modificação como política social, algo recorrente em modelos coordenados (PIERSON, 1995).

O PAR se coloca no sentido de resguardar a autonomia dos subgovernos, retomando o princípio constitucional brasileiro de restrição do poder central em relação aos subgovernos (center-constraining). A distribuição de poder mediante a previsão de regime de colaboração instituído pelo Decreto nº 6.094/07 dá a conotação de federalismo simétrico, em que os municípios possuem o mesmo grau de autonomia em relação ao governo central, pelo menos em seu texto normativo.

Ao mesmo tempo em que aceita a autonomia dos municípios, o PAR a restringe no momento em que estabelece critérios a serem obedecidos, fazendo o governo federal exercer o poder demos constraining que seria, teoricamente, dos subgovernos nacionais segundo a tese de Stepan (1999) para democracias majoritárias como o Brasil.

Conforme Pierson (1995), as políticas públicas quando são pensadas dentro de uma arena política visam garantir dois objetivos básicos: metas e proteção de posições institucionais. Ao priorizar a eficiência, o PAR se constitui em uma complexa tarefa, principalmente por querer estabelecer mecanismos de cooperação em um país cujo histórico de federalismo foi do tipo predatório. 
Analisamos que sua dificuldade política decorre da fragmentação evidenciada na path dependence (trajetória dependente) do país. Prescinde de ações verticais de controle e coordenação, que ao mesmo tempo não torne o governo central uma democracia que restringe o poder de suas subunidades. Ele poderia se tornar uma possibilidade de capacidade de coordenação da política educacional por meio do governo federal se deixasse de lado seu aspecto enviesado de demos constraining (restrição de poder).

No modelo cooperativo proclamado nele, as unidades federadas devem ser dotadas de autonomia decisória e capacidade de financiamento para que haja maior estímulo na execução da política, resultando em maior parceria e não subordinação dos entes, dado o histórico federalista brasileiro. Um dos impeditivos, neste sentido, como mecanismo que limita a autonomia das SEMEDs é a imposição pelo PAR de ações e subações, bem como estipulação de percentuais obrigatórios na aplicação dos recursos financeiros advindos das transferências voluntárias, visto que a liberdade de escolha dos subgovernos nacionais é restrita.

O PAR traz a problemática de inserir na arena política das Relações Intergovernamentais (IRGs) as Secretarias Municipais de Educação, o que pressupõe a gestão cotidiana dos problemas entre as unidades de governo (AGRANOFF, 1992). Enquanto arena intergovernamental, as SEMEDs representam lócus para experiências de um federalismo mais compartilhado, ao mesmo tempo em que elas podem influenciar ou serem influenciadas pelas políticas federais.

As Secretarias Municipais de Educação possuem interesses e atividades que constituem o sistema educacional brasileiro. Enquanto representantes dos subgovernos municipais são locais autônomos de autoridade política.

Argumentamos que a promulgação precoce de políticas como o PAR, que se proclamam descentralizadas, podem restringir as opções disponíveis por parte das SEMEDs que são arenas políticas de formulação de políticas educacionais. Políticas que não promovem a verdadeira descentralização 
podem até mesmo gerar custo maior aos governos federais, segundo Pierson (1995).

A partir de pesquisa empreendida em 4 (quatro) municípios maranhenses (Cantanhede/MA, Vargem Grande/MA, Palmeirândia/MA e Presidente Vargas/MA) foi possível observar as questões até agora aludidas, principalmente o caráter constrangedor (constraining) do modelo de planejamento educacional proposto pelo PAR.

Nas entrevistas realizadas nos municípios citados os 3 (três) Coordenadores Locais do PAR, 4 (quatro) Secretários Municiais de Educação e 2 (dois) Técnicos do MEC apontam uma concepção do PAR enquanto mecanismo de constrangimento do governo federal para seus subgovernos nacionais no tangente à autonomia do modelo de planejamento contido no PAR.

Quando os 9 ( nove) entrevistados destacam o processo de autonomia dos municípios no PAR, a sinopse é a sobreposição do governo federal em relação às suas subunidades. Este fator mostra que a federação brasileira (União) exerce o poder de democracia que constrange (demos constraining) que seria de seus subgovernos nacionais, contrariando a tese de Stepan (1999) de que federações seriam antidemocráticas justamente porque o governo federal est aria restringido por seus subgovernos nacionais.

Notamos o aspecto de democracia que constrange no debate dos entrevistados sobre a autonomia da Secretaria Municipal de Educação em relação ao Plano de Ações Articuladas, o que inviabiliza um regime de colaboração baseado na interdependência entre as partes sugerida pelo referencial teórico da Teoria do federalismo enquanto pacto a partir do argumento de Elazar (1987).

A questão abordada sobre a autonomia dos subgovernos nas entrevistas remonta um problema discutido por Pierson (1996) ao estudar as consequências dos padrões de governação instituídos por políticas públicas com aspectos do Estado de Bem-Estar Social.

Pierson (1996) argumenta que as instituições políticas dos países variam com o passar do tempo as regras do jogo. Segundo o autor, as instituições 
podem estabelecer as regras do jogo para as lutas políticas - influenciando as identidades de grupo, preferências políticas e escolhas de coalizão - e reforçam o poder de negociação de alguns grupos, enquanto desvalorizam outros.

A literatura da Ciência Política (LIJIPHART, 1999; ELAZAR, 1987; SCHARPF, 1988; PIERSON, 1995, 1996; WRIGHT, 1978) destaca que os sistemas federativos, ao adotarem decisões conjuntas, correm o risco da paralisia decisória ou o que eles denominam de resultados subótimos, que recaem na argumentação dos Coordenadores Locais do PAR dos municípios de Palmeirândia/MA e Vargem Grande/MA ao destacarem não haver diálogo entre os três entes federados, ficando um dos níveis sozinho no processo de execução da política, no caso as SEMEDs pesquisadas.

As entrevistas dos Técnicos do MEC seguem a mesma linha de discussão apresentada pelos Coordenadores Locais demonstrando que o PAR criou a paralisia decisória (HODDEN, 2004).

Os depoimentos dos Técnicos do MEC e dos Coordenadores Locais do PAR entrevistados expõem que o federalismo brasileiro é um pacto político incompleto, que possui o problema constante da ação governamental conjunta, pois, a Constituição de 1988 não criou os mecanismos para a coordenação das ações entre os entes federados. As entrevistas realizadas denunciam a falta de cooperação e interdependência entre União, governo estadual e municípios.

As discussões sobre a autonomia dos municípios destacam que o conjunto de restrições máximas (demos constraining) é a arena política do governo federal (quem realmente tem o poder de legislar sobre a política de planejamento educacional no Brasil).

Os Secretários Municipais de Educação entrevistados nesses municípios, refletindo sobre a temática autonomia dos municípios, destacam os mesmos problemas tangenciados pelos Técnicos do MEC e Coordenadores Local do PAR, argumentando que o processo é lento e burocrático, e também, nada colaborativo em termos reais de planejamento educacional. 
Como as ações do PAR são padronizadas muitas destas não contemplam as necessidades dos 4 (quatro) municípios pesquisados, o que gera descontentamento, onde "o desafio é fazer acontecer". Muito mais do que fazer acontecer, o desafio é fazer a União desenvolver ações no sentido de promover o federalismo cooperativo para as políticas de planejamento educacional.

O ente federado estadual, conforme os depoimentos coletados na pesquisa de campo, deve cumprir seu papel e implementar as ações com previsão de colaboração presentes no PAR do Estado. É por este motivo que - PAR se apresenta descoordenado e desarticulado em relação às demandas municipais no tangente ao planejamento educacional.

A partir das entrevistas realizadas, defendemos que existe uma fragmentação organizacional do modelo federalista brasileiro ainda pautado na autoridade dependente descrita por Wright (1978), impondo obstáculos às formas redistributivas não só de recursos, mas também da tomada de decisões, ocorrendo o fenômeno de superimposição (PIERSON, 1995) se tomarmos O PAR como uma política pública redistributiva do federalismo brasileiro. Criando a responsabilização (accountability) e performatividade aos municípios que aderiram ao Plano de Ações Articuladas.

Com base nas entrevistas, analisamos que as SEMEDs pesquisadas não possuem clareza sobre o que seja um modelo gerencial de planejamento ou democrático de fato. Talvez esse seja o motivo, nestas instituições pesquisadas, de não haver a implementação nem de um ou outro. Nem mesmo o burocrático, nos fazendo afirmar que o hibridismo gerencial pende muito mais para a desarticulação e descoordenação do planejamento educacional.

Segundo a Técnica B/MEC entrevistada durante a pesquisa de campo, o que existe a partir do Plano de Ações Articuladas é um processo de atribuição das responsabilidades que antes eram do governo federal e agora passam para os estados e municípios. 
Ao eleger o regime de colaboração e reafirmar que as autonomias seriam resguardadas, existe a presença da pressuposição de vários atores institucionais, dentre os quais as SEMEDs. O documento PAR, como está escrito, enfatiza que cada um dos entes locais é autônomo de autoridade política. Deveriam possuir capacidade não só para formular suas próprias políticas, mas também para influenciar as políticas que surgem no centro.

O lugar que ele confere às SEMEDs confirma um argumento de Pierson (1995) que aleta para o fato de que as regras est abelecidas pelos sistemas federativos influenciam na formulação das políticas sociais. O texto do PAR segue a assimetria política do federalismo brasileiro, cujo espaço político dado aos governos locais enquanto espaço autônomo é restritivo.

Cada vez mais o papel da União no processo de implementação das políticas educacionais torna-se mínimo, aparecendo apenas para controlar os entes federados, não se preocupando em manter a política. Dos 4 (quatro) Secretários Municipais de Educação entrevistados, 3 (três) destacam este mesmo processo de responsabilização aos municípios por parte do governo federal evidenciado na fala da Técnica B/MEC. Admitem também que apesar de serem responsabilizados não sobrecarregam a Secretaria Municipal de Educação a partir da ação gerada.

As entrevistas sobre a responsabilização das demandas aos municípios referentes ao planejamento educacional revelam que a organização fragmentada dos subgovernos maranhenses, atrelada às práticas clientelistas deste estado brasileiro impede que estes exerçam o poder de democracia que constrange (próprio de um federalismo cooperativo/interdependente) e façam sua parte na função de entes federados de uma nação que se propõe interdependente e cooperativa constitucionalmente na área da educação.

Por sua natureza institucional, as SEMEDs podem, enquanto ente autônomo, barganhar junto ao governo central, considerando o princípio das IGR de desenvolvimento ou execução de políticas públicas, requerendo a interdependência entre os governos e uma coordenação intergovernamental. Pode criar mecanismos confiáveis que articulem os 
entes sem thes ferir a autonomia, um princípio básico no modelo de autoridade interdependente de Wright (1978).

Por ser um arranjo federativo, o PAR foi desenhado para dar prioridade à colaboração, em vez da autonomia entre os entes federados, pois a integração social e a melhoria da qualidade do IDEB são seus maiores objetivos. Isso coloca aos governos locais um problema denominado por Scharpf (1988) de armadilha de decisão conjunta, típico do modelo cooperativo.

Apesar do PAR possuir características de um governo federal não limitado por suas subunidades na tomada de decisões, devemos lembrar que dentro do federalismo não somente os atores sociais são afetados pelo desenho constitucional de sua federação (OBLINGER; LEIBFRIED; CASTLES, 2005). Mudanças podem ser feitas de acordo com a situação de cada política, de maneira incremental e informal, sem que se faça um novo texto político (WACHENDORFER-SCHMIDT, 2007).

Com sua instituição pelo governo federal, os subgovernos ficaram reduzidos em sua importância como formuladores de políticas públicas. Aparecendo como implementadores de políticas de um governo central que no momento não se mostra constrangido pelos outros entes federados.

O processo de se fazer uma política (policy making process) como o PAR a partir das análises efetuadas revela-se complexo, porque ele é o resultado de uma multiplicidade de atores que possuem poderes diversificados que se influenciam mutuamente e estabelecem diferentes regras no jogo de coalizão.

Configura o modo de barganhas constantes nesta arena de negociação que se caracteriza o PAR para os municípios partícipes desta pesquisa, uma vez que com ele barganham junto ao governo federal a responsabilidade na oferta da educação.

\section{CONSIDERAÇÕES FINAIS}

Com base no exposto ao longo deste artigo infere-se que a questão a autonomia municipal que, por sua, depende da criação e a 
institucionalização do seu Sistema Municipal de Educação, decorrem de um conjunto de processos e contextos dos quais os dispositivos legais e as políticas educacionais no Brasil são frutos.

Portanto, o planejamento, a execução e a avaliação das ações educativas dos municípios dependem do jogo de intenções e interesses divergentes, disputas, ressignificações, articulações e reconfigurações em diferentes níveis, instâncias e esferas governamentais.

Desse modo, o regime de colaboração proposto na LDBEN $n^{\circ}$ 9.394/1996 e no PNE (2014-2024) depende das regulamentações que, muitas das vezes são prorrogadas, dada a visão clientelista e patrimonialista ainda presente em várias instâncias governamentais. Nota-se que o planejamento educacional como política de Estado e não de governo torna-se um desafio, diante das desigualdades que marcam a educação brasileira e impedem a consolidação de um federalismo de fato cooperativo.

Nesse sentido, a pesquisa evidenciou que na construção da arena política do Plano de Ações Articuladas no Maranhão, na busca do federalismo cooperativo para o planejamento educacional, dois atores se fizeram presentes no jogo da barganha de um federalismo de coalizão: a União e os municípios, que jogaram a partir da armadilha da decisão conjunta a construção de um federalismo incompleto.

Com o PAR, o governo federal regulou como os sujeitos que o executam devem agir, criando a responsabilização (accountability) no alcance dos resultados desejados. Deste modo, a gestão educacional presente no discurso da União legitima o padrão de qualidade que se pauta no IDEB. A pesquisa revela que a gestão no PAR desenvolvida pelas SEMEDs se ancora em um modelo de regulação das ações que visam produzir práticas gerencialistas nestas instituições que agravam a tomada de decisões por meio da performatividade que deve ser alcançada.

Sua adoção traz conflitos às formas de gestão presentes nas SEMEDs em virtude de o PAR ser definidor das regras do jogo, revelando-se um hibridismo da gestão educacional que pende para total atuação descoordenada. Observamos que o discurso da responsabilização nele 
contido produz práticas de gestão educacional mecanicistas nos municípios pesquisados que não refletem sobre as ações, apenas executam-nas.

Não se pode esquecer que em países federais como o Brasil, a interdependência entre os subgovernos é processual, porém este fator nem sempre produz arranjos de governança eficazes ou imunes aos conflitos, sendo $O$ aspecto conflitante presente na implementação do PAR nos municípios pesquisados por prescindir de mecanismos formais de cooperação e compartilhamento. As IGRs presentes na Constituição Federal brasileira deveriam regular as condições exógenas do PAR, dinamizando as tarefas entre os entes federados na implementação das ações previstas.

O bolo de mármore (camadas que se interligam) que caracteriza o federalismo cooperativo iria permitir a interposição dos poderes e compartilhamento das responsabilidades entre os três entes federados do Brasil, porém, este aspecto não se concretizou via PAR dentro das SEMEDs pesquisadas. As IGRs no PAR evidenciam o federalismo incompleto do país, justamente por não trazerem os aspectos citados.

A descentralização, conforme a literatura internacional mencionada na tese, não é condição primeira para o federalismo, mas sim a não centralização. As SEMEDs dentro desta pesquisa vieram atuando com um modelo de gestão ora burocrático, ora gerencial e ora desarticulado das ações pactuadas com a União.

Os resultados da pesquisa sugerem que o PAR não efetiva a gestão por resultados proposta em suas normativas legais e nem as SEMEDs conseguem propor sua concepção de gestão educacional, criando um hibridismo que ora pende para o gerencialismo e performatividade, ora para a burocracia, ora para total atuação descoordenada e desarticulada.

Em relação à gestão proferida pelas SEMEDs a pesquisa mostra que estas instituições não possuem uma concepção própria de gestão educacional e acabam atuando de forma descoordenada e desarticulada. A pesquisa concluiu que o PAR é uma superimposição do governo federal aos subgovernos nacionais que conflita com as formas de gestão destas instituições acostumas com uma lógica não gerencial. Esta superimposição 
faz a União ser o centro do federalismo brasileiro que é na realidade um pacto incompleto.

Os municípios pesquisados mostraram como se deu o planejamento educacional proclamado nas Resoluções n² 29/07, n 47/07 e n 14/12 do FNDE e no Decreto $n^{\circ}$ 6.094/07. Ele é, pelas normativas citadas e pelas entrevistas coletadas, uma arena negociativa em que um dos lados sai perdendo (as SEMEDs), na qual figura um pacto federativo incomplet o e um hibridismo no campo do planejamento educacional.

\section{REFERÊNCIAS}

ATALLI, J. A crise e agora? Lisboa: Tribuna, 2009.

BORDIGNON, G. Gestão da educação no município: sistema, conselho e plano. São Paulo: Instituto Paulo Freire, 2009.

BRASIL. Constituição da República Federativa do Brasil. 1988. Disponível em:http//www.planato.gov.br/ccivil_03/constituição/principal.htm. Acesso em janeiro de 2017.

BRASIL. Lei $\mathbf{N}^{\circ} \mathbf{9 . 3 9 4}$ de 20 de dezembro de 1996. Estabelece as Diretrizes e Bases da Educação.

BRASIL. Lei $\mathbf{N}^{\circ}$ 13.005, de 25 de junho de 2014. Aprova o Plano Nacional de Educação. Disponível em: http//www.planto.gov.br//ccivil_03_ato20112014/2014/ lei/l13003.htm. Acesso em janeiro de 2017.

BRASIL. Resolução n 14/2012 do FNDE. Brasília, 2012.

BRASIL. Institui o Sistema Nacional de Educação: agenda obrigatória para o país. http://pne.mec.gov.br/SNF_junho de 2015.pdf. Acesso em março de 2017.

BRASIL. Plano Plurianual (2008-2011). Brasília: MP, 2007a.

BRASIL. Compromisso todos pela educação: passo a passo. Brasília: 2007b.

BRASIL. O plano de desenvolvimento da educação (PDE): razões, princípios e programas. Brasília, 2007c.

BRASIL. Decreto $n^{\circ}$ 6.094, de 24 de abril de 2007d. 
BRASIL. Presidência da República. Ministério da Educação. Fundo Nacional de Desenvolvimento da Educação. Conselho deliberativo. RESOLUÇÃO/ CD/ FNDE /N. ${ }^{\circ}$ 029, de 20 de junho de 2007e.

BRASIL. Fundo Nacional de Desenvolvimento da Educação. Conselho deliberativo. RESOLUÇÃO/CD/FNDE N 047, de 20 de setembro de $2007 f$.

CABRAL NETO, A. et. al. Plano municipal de educação: elaboração, acompanhamento e avaliação no contexto do PAR. In: Revista Brasileira de Política e Administração de Educação. v.23, n. 1 jan-abr 2016 p. 47-67.

CLARKE, J.; NEWMAN, J. The managerial state. London: Sage publications, 1997.

CLARKE, J.; NEWMAN, J. Managing social policy. London: Sage publications, 1994.

CURY, C. R. J. Sistema Nacional de Educação: uma reflexão provocative ao debate. In: $O$ sistema nacional de educação: diversos olhares 80 anos após $O$ Manifesto: Brasília: MEC/SAE, 2014 p. 30-39.

ELAZAR, D. J. Exploring Federalism. Tuscaloosa: The University of Alabama Press, 1987.

ELAZAR, D. J. Federalism and the way to peace. Kingston: Institute of Intergovernmental Relations, 1994 (Refletions, n.13).

ELAZAR, D. J. Federalism: an overview. Pretoria: HSRC Publishers, 1995.

GADOTTI, M. ROMÃO J. E. Município e Educação. São Paulo: Cortez, 1993.

HODDEN, J. Comparative federalism and descentralization: on meaning and measurement. In: Comparative politics, july, 2004. p. 481-500.

LIJPHART, A. Patterns of democracy-government forms and performance in the thirty-six coutriens. Yale University Press, 1999.

OBINGER, H.; LEIBFRIED, S.; CASTLES, F. G. (Orgs). Federalism and the welfare state: New World and European Experiences. Cambridge University Press, 2005.

PIERSON, P. Fragmented Welfare States: Federal Institutions and the Development of Social Policy. In: Governance. Cambridge, Mass. v. 8, n. 4, October, 1995 (p. 449-478).

PIERSON, P. The New Politics of the Welfare State. In: World Politics, 1996. 
RIKER, W. Federalism, Origin, Operation, Significance. Little: Brown and Company, 1964.

SA VIANI, D. Organização da educação nacional: sistema e conselho de nacional de educação, plano e fórum nacional de educação. In: Educação e Sociedade. v 31 n. 112 . São Paulo: Cedes, jul \set. 2010. p. 769-787.

SCHARPF, F. The Joint Decision Trap: Lessons from German Federalism and European Integration. In: Public Administration, v. 66, p. 80-117, Autumm, 1988.

SCHULTZE, Rainer-Olaf. Federalismo. In: FUNDAÇÃO KONRAD ADENAUER STIFTUNG. O federalismo na Alemanha. Traduções. São Paulo: Konrad Adenaver Stiftung, 1995, p.15-32.

STEPAN, A. Toward a New Comparative Analysis of Democracy and Federalism: Demos Constraining and Demos Enabling Federations. Paper presented at the Conference on Federalism, Democracy, and Public Policy. Centro de Investigación y Docencia Económicas, Mexico City, Mexico, June 14-15, 1999. p. 1-54.

WACHENDORFER-SCHMIDT, U. Collaborative federalism in Germany: keeping the system in the eye of the storm. In: (ed). Federalism and political performance. London: Routledge, 2007. P.77-107.

WRIGHT, D. S. Del federalismo a las relaciones intergubernamentales en los Estado Unidos de America: una nueva perspectiva de la actuación reciproca entre el gobierno nacional, estatal y local. In: Revista de Estudios Políticos, 1978, n. 6, p. 5-28.

Recebido em: 07 de setembro de 2018.

Aprovado em: 12 de abril de 2019. 